\title{
Corrigendum: A p-tert-Butyldihomooxacalix[4]arene Based Soft Gel for Sustained Drug Release in Water
}

\author{
Hao Guo ${ }^{1,2}$, Runmiao Zhang ${ }^{1,2}$, Ying Han ${ }^{1 *}$, Jin Wang ${ }^{2 *}$ and Chaoguo Yan ${ }^{1}$ \\ ${ }^{1}$ School of Chemistry and Chemical Engineer, Yangzhou University, Yangzhou, China, ${ }^{2}$ School of Chemistry and Chemical \\ Engineer, Nantong University, Nantong, China
}

Keywords: calixarenes, gel, controlled release, macrocyclic compounds, Ugi reaction

\section{A Corrigendum on}

A p-tert-Butyldihomooxacalix[4] arene Based Soft Gel for Sustained Drug Release in Water by Guo, H., Zhang, R., Han, Y., Wang, J., and Yan, C. (2020). Front. Chem. 8:33. doi: $10.3389 /$ fchem.2020.00033

In the original article, there was an error. In the title, " $p$-tert-Tutyldihomooxacalix[4]arene" was misspelled. A correction has been made to the title which should read

OPEN ACCESS

Edited by:

Tangxin Xiao,

Changzhou University, China

Reviewed by:

Shengyi Dong,

Hunan University, China

*Correspondence:

Ying Han

hanying@yzu.edu.cn

Jin Wang

wangjin107@ntu.edu.cn

Specialty section:

This article was submitted to

Supramolecular Chemistry,

a section of the journal

Frontiers in Chemistry

Received: 15 June 2020

Accepted: 13 July 2020

Published: 21 August 2020

Citation:

Guo $H$, Zhang R, Han Y, Wang J and Yan C (2020) Corrigendum: A p-tert-Butyldihomooxacalix[4]arene Based Soft Gel for Sustained Drug Release in Water. Front. Chem. 8:721.

doi: 10.3389/fchem.2020.00721
"A p-tert-Butyldihomooxacalix[4]arene Based Soft Gel for Sustained Drug Release in Water".

There was an error in the abstract: "one $\mathrm{CH}_{2}$ bridge is replaced by one -O- group" was misspelled. A correction has been made to the first sentence abstract which should read as follows: "P-tert-butyldihomooxacalix[4]arene is a well-known calix[4]arene analog in which one $\mathrm{CH}_{2}$ bridge is replaced by one $-\mathrm{CH}_{2} \mathrm{OCH}_{2}$ - group."

Also, "one $\mathrm{CH}_{2}$ bridge is replaced by one -O- group" was misspelled in Introduction, in the first sentence of the second paragraph. The corrected sentence should read as follows: "P-tert-butyldihomooxacalix[4]arene is a well-known $p$-tert-butylcalix[4]arene analog in which one $\mathrm{CH}_{2}$ bridge is replaced by one $-\mathrm{CH}_{2} \mathrm{OCH}_{2}$ - group (Marcos et al., 2002)."

In the original article, the following reference was not cited in the article: Liu, Y., Zhao, L.-L., Sun, J., and Yan, C.-G. (2018). Convenient synthesis and coordination properties of p-tert-butyldihomooxacalix[4] arene mono-schiff bases. Polycyclic Aromat. Compd. 40, 644-659. doi: 10.1080/10406638.2018.1469520. The citation has now been inserted in Materials and Methods, in section Synthesis of p-tert-Butyldihomooxacalix[4]-Arene 1, in the first paragraph which should read:

P-tert-butyldihomooxacalix[4] arene 4 (4.0 g, $5.9 \mathrm{mmol})$, Cl-alkoxy-substituted salicylaldehyde (1.8 g, $9.0 \mathrm{mmol}), \mathrm{K}_{2} \mathrm{CO}_{3}(1.2 \mathrm{~g}, 9.0 \mathrm{mmol})$, and $\mathrm{KI}(1.5 \mathrm{~g})$ was added in $150 \mathrm{ml}$ acetone. The mixture was stirred at $75^{\circ} \mathrm{C}$ for $24 \mathrm{~h}$ (Scheme S1). After removal of the inorganic salt, the solvent was evaporated, and the residue was purified by chromatography on silica gel (petroleum ether/ethyl acetate, $v / v 5: 1$ ) to give 2 as a white solid (Liu et al., 2018). Then 2 (0.1 mmol, $0.885 \mathrm{~g}$ ), benzyl amine $(0.1 \mathrm{mmol}, 0.107 \mathrm{~g})$, benzoic acid $(0.1 \mathrm{mmol}, 0.122 \mathrm{~g})$, and isocyancyclohexane $(0.1 \mathrm{mmol}$, $0.109 \mathrm{~g}$ ) were added into $7 \mathrm{ml}$ methanol for reacting for $36 \mathrm{~h}$. Then the solvent was evaporated, and the residue was purified by chromatography on silica gel (petroleum ether/ethyl acetate, v/v 3:1) to give 1 as a light yellow solid.

Additionally, in the original article, Scheme 1 indicates compound $\mathbf{1}$ in the cone and partial cone conformations, but these two conformers are not explained. A correction has been made to Results and Discussion, section Gelation tests, end of the second paragraph by adding the 
following sentence: "It should be pointed out that the compound $\mathbf{1}$ we used to construct gel contains both conformers."

\section{REFERENCES}

Liu, Y., Zhao, L.-L., Sun, J., and Yan, C.-G. (2018). Convenient synthesis and coordination properties of p-tert-Butyldihomooxacalix[4]arene mono-schiff bases. Polycyclic Aromat. Compd. 40, 644-659. doi: 10.1080/10406638.2018.1469520

Marcos, P., Ascenso, J., and Pereira, J. L. C. (2002). Synthesis and NMR conformational studies of p-tert-butyldihomooxacalix[4]arene derivatives bearing pyridyl pendant groups at the lower rim. Eur. J. Org. Chem. 2002, 3034-3041. doi: 10.1002/1099-0690(200209)2002:17<3034::AID-EJOC3034>3. $0 . \mathrm{CO} ; 2-\mathrm{I}$
The authors apologize for these errors and state that these do not change the scientific conclusions of the article in any way. The original article has been updated.

Copyright (c) 2020 Guo, Zhang, Han, Wang and Yan. This is an open-access article distributed under the terms of the Creative Commons Attribution License (CC BY). The use, distribution or reproduction in other forums is permitted, provided the original author(s) and the copyright owner(s) are credited and that the original publication in this journal is cited, in accordance with accepted academic practice. No use, distribution or reproduction is permitted which does not comply with these terms. 